\title{
A Cross-sectional Study: Association Between sarcopenia and Osteoporosis in Type 2 Diabetes Mellitus Patients With a High Glycated Hemoglobin Level
}

\section{Fang Lingna ( $\square$ 30907988@qq.com )}

First Peoples Hospital of Kunshan https://orcid.org/0000-0003-3465-8604

\section{Shao Zhong}

First Peoples Hospital of Kunshan

\section{Dan Ma}

First Peoples Hospital of Kunshan

\section{Bing Lu}

First Peoples Hospital of Kunshan

\section{Liwen Shen}

First Peoples Hospital of Kunshan

\section{Li Zhang}

First Peoples Hospital of Kunshan

\section{Fengyan Tang}

First Peoples Hospital of Kunshan

Heping Sun

First Peoples Hospital of Kunshan

\section{Research}

Keywords: type 2 diabetes mellitus, glycated hemoglobin, sarcopenia, osteoposis

Posted Date: July 9th, 2020

DOI: https://doi.org/10.21203/rs.3.rs-39303/v1

License: @ (i) This work is licensed under a Creative Commons Attribution 4.0 International License. Read Full License 


\section{Abstract}

Background: Sarcopenia and osteoporosisare commonly observed in individuals with type 2 diabetes mellitus (T2DM).Thus, this study investigated the association between sarcopenia and osteoporosis in T2DM patients with a highglycated hemoglobin (HbA1c)level.

Methods: This study recruited 98 Chinese patients with T2DM who were aged $\geq 50$ years, and their body compositions were evaluated using dual-energy X-ray absorptiometry. Moreover, the fFasting blood glucose, $\mathrm{HbA1C}$, B collagen-specific sequences (B-CTX), osteocalcin(OC), propeptide of type 1 procollagen(P1NP), 25hydroxy vitamin Dlevels were evaluated.Sarcopenia was defined as skeletal muscle mass index (SMI) $<7.0$ $\mathrm{kg} / \mathrm{m}^{2}$ for men and $<5.4 \mathrm{~kg} / \mathrm{m}^{2}$ for women.

Results: There were 42 men and 56 women, with an average age of $65.86 \pm 8.32$ years and $\mathrm{HbA} 1 \mathrm{c}$ level of $8.59 \% \pm 1.87 \%$. The prevalence rates ofsarcopenia, osteopenia, and osteoporosis were $48.0 \%, 37.8 \%$, and $33.6 \%$, respectively.Moreover, the prevalence of osteoporosis was significantly higher in women than in men ( $50 \%$ vs. $11.9 \%, \mathrm{P}=0.000$ ). The prevalence of sarcopenia was significantly higher in patients with $\mathrm{HbA} 1 \mathrm{c}$ levels $>9.0 \%$ than in those with $\mathrm{HbA} 1 \mathrm{c}$ levels $<9.0 \%(62.2 \%$ vs. $39.3 \%, \mathrm{P}=0.037)$. However, the prevalence of osteopenia and osteoporosis in patients with $\mathrm{HbA1c}$ levels $>9.0 \%$ differed from those with $\mathrm{HbA} 1 \mathrm{c}$ levels < $9.0 \%(29.5 \%$ vs. $51.4 \%$ for osteopenia, $32.8 \%$ vs. $35.1 \%$ for osteoporosis; $P=0.022)$. The height and weight of the osteoporosis group significantly decreased compared with those of the normal bone mineral density (BMD), whereas the serum BCTX, OC, and PINP levels significantly increased.The SMI, trunk muscles, skeletal muscle parameters, lumbar spine bone mineral content (BMC), lumbar spine BMD, femoral BMC, and femoral BMD decreased significantly in T2DM patients with osteoporosis.Sarcopeniawas associated with a higher height (odds ratio $[\mathrm{OR}]=1.524,95 \%$ confidence interval $[\mathrm{Cl}]=1.196-1.698, \mathrm{P}=0.000)$, lower body weight $(\mathrm{OR}=$ $0.735,95 \% \mathrm{Cl}=0.640-0.844, \mathrm{P}=0.000)$, and higher body fat content $(\mathrm{OR}=1.211,95 \% \mathrm{Cl}=1.046-1.402, \mathrm{P}=$ 0.011). Meanwhile, osteoporosis was correlated to a lower SMI $(\mathrm{OR}=0.178,95 \% \mathrm{Cl}=0.044-0.817, \mathrm{P}=0.015)$.

Conclusions: Ahigh HbA1c level was associated with a higher prevalence of sarcopenia and osteoporosis in T2DM patients, and low muscle masswas considered a risk factor for osteoporosis inthis group of patients.

\section{Background}

China has a large population, and the number of Chinese aged > 50 years reached 280 million in 2019. Moreover, the country has the highest number of diabetic individuals worldwide. The prevalence rates of diabetes among individuals aged $40-59$ and $>60$ years were $12.9 \%$ and $20.2 \%$, respectively [1]. Type 2 diabetes mellitus (T2DM) is a chronic inflammatory disease characterized by glucose metabolism disorders and insulin resistance, and blood glucose disorder and its related complications affect quality of life among elderly patients.

In T2DM patients, the skeletal muscle is significantly reduced, and sarcopenia, which is characterized by loss of skeletal muscle mass and decreased function, is a common complication. Age, exercise, nutrition, neurodegenerative changes, and chronic inflammation are correlated to the development of sarcopenia [2]. Patients with sarcopenia are at increased risk of falls and fractures, which can lead to incapacitation, loss of self-care, and even death [3]. The muscle mass of the limbs of diabetic patients is significantly low. In a 
previous study, elderly diabetic patients with a long duration of diabetes had a worse degree of sarcopenia [4]. Moreover, in the study of Korean diabetic individuals aged over 60 years, the prevalence rates of sarcopenia were $19 \%$ in men and $27 \%$ in women; the prevalence rate was $27.4 \%$ in a population in Singapore, and it was significantly higher in individuals with T2DM than in those without $[5,6]$.

Osteoporosis is also a common disease correlated to aging, and its incidence increases with age. Type 2 diabetes and osteoporosis are affected by age and lifestyle and are more commonly observed in elderly individuals. The Rotterdam study investigated data about bone mineral density (BMD) and fracture in 792 T2DM patients and 5,863 non-diabetic patients, and results showed that T2DM patients had a higher femur and lumbar spine BMD. However, the risk of fracture increased by 1.33 times [7]. In a previous study, the incidence of hip, vertebra, and forearm fractures in osteoporosis patients with T2DM significantly increased [8].

Patients with sarcopenia are at increased risk of falls and fractures [9]. The association between sarcopenia and osteoporosis in patients with T2DM, particularly those with poor blood glucose control, is unclear. Thus, this study investigated the association between sarcopenia and osteoporosis in T2DM patients with a high glycated hemoglobin (HbA1c) level.

\section{Methods}

Study design and participants

\section{Patients}

Patients with T2DM who were aged $\geq 50$ years and were admitted at the Department of Endocrinology, Kunshan Hospital Affiliated with Jiangsu University from December 2018 to January 2020 were included in the study. The exclusion criteria included patients with thyroid disease, renal failure, and cerebral infarction and those who received hormone therapy, such as growth hormone, thyroid hormone, and steroid. This study was approved by the ethics committee of Kunshan Hospital Affiliated with Jiangsu University. All participants obtained a written informed consent.

\section{Parameters}

Data about the participants' weight, height, and systolic blood pressure and the course of diabetes were collected.

\section{Dual-energy X-ray absorptiometry}

Whole-body dual-energy X-ray absorptiometry (DXA) (Hologic Discovery, the USA) was used to measure trunk muscle mass, body fat content, bone mineral content (BMC), BMD, skeletal muscle mass index (SMI), and skeletal muscle parameter. SMI was calculated using the following formula: appendicular skeletal muscle mass (ASM) (kg) / height ${ }^{2}\left(\mathrm{~m}^{2}\right)$. Meanwhile, skeletal muscle parameter was calculated using the following formula: skeletal muscle content $(\mathrm{kg})$ / body weight $(\mathrm{kg})$. The diagnostic criteria for sarcopenia in Asians are 
$\mathrm{SMl}<7.0 \mathrm{~kg} / \mathrm{m}^{2}$ for men and $<5.4 \mathrm{~kg} / \mathrm{m}^{2}$ for women [10]. Normal bone mass was defined as T value $>-1.0$, osteopenia as $-1.0>$ T value $>-2.5$, and osteoporosis as $\mathrm{T}$ value $<-2.5$.

\section{Laboratory examination}

The fasting blood samples of participants were collected to determine the levels of fasting blood glucose (FBG), HbA1C, B collagen-specific sequences (B-CTX), osteocalcin (OC), propeptide of type 1 procollagen (P1NP), 25-hydroxy vitamin D (25(OH)D).

\section{Statistical analysis}

The SPSS Statistics 22 was used for statistical analysis. All data were expressed as mean \pm standard deviation. For comparison of continuous variables between the groups, $t$-test or analysis of variance (continuous variable) was used. Categorical variables were expressed as percentages, and $\chi 2$ test (categorical variable) was used. A single-factor logistic regression analysis was performed to assess the factors associated with sarcopenia and osteoporosis, and a step-by-step process was utilized to select covariates via a multiple logistic regression analysis. Using a logistic regression model, the odds ratio (OR) and 95\% confidence interval $(\mathrm{Cl})$ were calculated. A P value $<0.05$ was considered statistically significant.

\section{Results}

A total of 98 inpatients with T2DM who were aged $\geq 50$ years were included in this study. Among the participants, there were 42 men and 56 women, with an average age of $65.86 \pm 8.32$ years. Moreover, the average duration of T2DM was $13.69 \pm 7.98$ years. The average $\mathrm{HbA} 1 \mathrm{c}$ level of all patients was $8.59 \% \pm 1.87 \%$ $(n=17, \mathrm{HbA} 1 \mathrm{c}$ level $<7.0 \% ; n=44, \mathrm{HbA} 1 \mathrm{c}$ level $>7.0 \%$ and $<9.0 \%$; and $n=37$, HbA1c level $>9.0 \%$ ). Table 1 shows the clinical characteristics of the participants. Compared with patients with $\mathrm{HbA} 1 \mathrm{c}$ levels $<7.0 \%$, patients with $7.0 \%<\mathrm{HbA} 1 \mathrm{c}$ level $<9.0 \%$ and $\mathrm{HbA} 1 \mathrm{c}$ level $>9.0 \%$ had a longer disease course and significantly higher FBG and HbA1c levels. With the increase in HbA1c levels, the body fat content of patients with T2DM increased. Moreover, the SMI and skeletal muscle parameters decreased. However, the results were not statistically significant. 
Table 1

Characteristics of T2DM patients stratified by $\mathrm{HbA} 1 \mathrm{c}$.

\begin{tabular}{|c|c|c|c|c|}
\hline & $\mathrm{HbA} 1 \mathrm{c}<7.0 \%$ & $7.0 \%<\mathrm{HbA} 1 \mathrm{c}<9.0 \%$ & $\mathrm{HbA} 1 \mathrm{c}>9.0 \%$ & $\mathbf{P}$ \\
\hline$n$ & 17 & 44 & 37 & \\
\hline Age (y) & $65.41 \pm 7.11$ & $65.23 \pm 8.51$ & $66.67 \pm 8.80$ & 0.733 \\
\hline Duration of diabetes $(\mathrm{y})$ & $8.84 \pm 7.47$ & $14.64 \pm 7.52^{\star}$ & $14.50 \pm 8.21^{\star}$ & 0.030 \\
\hline Height (cm) & $165.00 \pm 9.73$ & $161.30 \pm 8.80$ & $157.53 \pm 19.08$ & 0.164 \\
\hline Weight (Kg) & $65.59 \pm 10.47$ & $65.59 \pm 13.01$ & $64.57 \pm 12.10$ & 0.925 \\
\hline $\mathrm{SBP}(\mathrm{mmHg})$ & $136.24 \pm 17.24$ & $143.48 \pm 21.19$ & $137.39 \pm 22.05$ & 0.316 \\
\hline $\mathrm{FBG}(\mathrm{mmol} / \mathrm{L})$ & $5.93 \pm 1.65$ & $8.08 \pm 2.02^{\star}$ & $9.89 \pm 3.85^{\star} \#$ & 0.000 \\
\hline HbA1c (\%) & $6.09 \pm 0.59$ & $7.99 \pm 0.53^{*}$ & $10.50 \pm 1.34^{\star} \#$ & 0.000 \\
\hline BCTX (ng/ml) & $0.31 \pm 0.12$ & $0.29 \pm 0.17$ & $0.32 \pm 0.19$ & 0.706 \\
\hline $\mathrm{OC}(\mathrm{ng} / \mathrm{ml})$ & $11.00 \pm 2.92$ & $12.13 \pm 5.83$ & $11.03 \pm 4.88$ & 0.561 \\
\hline P1NP (ng/ml) & $39.18 \pm 11.88$ & $39.91 \pm 22.30$ & $37.86 \pm 16.96$ & 0.890 \\
\hline 25-OH-D (ng/ml) & $23.29 \pm 8.29$ & $19.68 \pm 8.09$ & $21.08 \pm 9.22$ & 0.289 \\
\hline Body fat $\%$ & $29.28 \pm 6.50$ & $31.88 \pm 5.67$ & $32.39 \pm 6.99$ & 0.237 \\
\hline $\mathrm{SMI}\left(\mathrm{kg} / \mathrm{m}^{2}\right)$ & $6.46 \pm 1.06$ & $6.34 \pm 1.00$ & $6.15 \pm 1.29$ & 0.511 \\
\hline Trunk MM (kg) & $21.67 \pm 44.06$ & $21.00 \pm 40.59$ & $20.51 \pm 39.92$ & 0.629 \\
\hline Skeletal muscle parameter (\%) & $59.82 \pm 6.43$ & $57.61 \pm 6.30$ & $56.65 \pm 7.39$ & 0.285 \\
\hline Lumbar spine BMC (g) & $59.93 \pm 15.80$ & $57.81 \pm 16.97$ & $60.72 \pm 21.45$ & 0.775 \\
\hline Femur BMC (g) & $32.51 \pm 10.01$ & $31.31 \pm 9.11$ & $30.00 \pm 8.49$ & 0.621 \\
\hline Lumbar spine BMD $\left(\mathrm{g} / \mathrm{cm}^{2}\right)$ & $0.90 \pm 0.12$ & $0.91 \pm 0.19$ & $0.94 \pm 0.20$ & 0.694 \\
\hline \multicolumn{4}{|l|}{$\left(\mathrm{g} / \mathrm{cm}^{2}\right)$} & 0.392 \\
\hline $\begin{array}{l}\text { Notes: Data are expressed as th } \\
<0.05 ; \text { \# refers to patients with } \\
\text { FBG = fasting plasma glucose; } \\
\text { osteocalcin; P1NP = propeptide } \\
\text { muscle index; Trunk MM = Trunk }\end{array}$ & $\begin{array}{l}\text { an } \pm \text { standard } \\
<\mathrm{HbA1c}<9.0 \% \\
\mathrm{c}=\text { glycated he } \\
\text { pe } 1 \text { procollag } \\
\text { scle mass; BM }\end{array}$ & $\begin{array}{l}\text { ation or \%. * refers tc } \\
=0.05 . \text { Abbreviations } \\
\text { globin; B-CTX = B col } \\
5-\mathrm{OH}-\mathrm{D}=25 \text {-hydroxy } \\
\text { jone mineral conten }\end{array}$ & $\begin{array}{l}\text { tients with HbA1c } \\
P=\text { systolic blooc } \\
\text { m specific sequer } \\
\text { min D; SMI = skel } \\
\text { ID = bone minera }\end{array}$ & $\begin{array}{l}7.0 \%, P \\
\text { essure; } \\
\text { s; OC = } \\
\text { l } \\
\text { ensity. }\end{array}$ \\
\hline
\end{tabular}

Among the patients, 47 (48.0\%) were diagnosed with sarcopenia, 37 (37.8\%) with osteopenia, and 33 (33.6\%) with osteoporosis. The prevalence of osteoporosis was significantly higher in women than in men $(50 \% \mathrm{vs}$. $11.9 \%, P=0.000)$. However, there was no significant difference in the prevalence of sarcopenia. Moreover, the prevalence of sarcopenia and osteoporosis between patients aged $<65$ years and those aged $>65$ years did 
not significantly differ. Meanwhile, the prevalence of sarcopenia was significantly higher in patients with $\mathrm{HbA} 1 \mathrm{c}$ levels $>9.0 \%$ than in those with HbA1c levels $<9.0 \%(62.2 \%$ vs. $39.3 \%, \mathrm{P}=0.037)$. Moreover, the prevalence of osteopenia and osteoporosis differed in patients with $\mathrm{HbA1c}$ levels $<9.0 \%$ and $\mathrm{HbA} 1 \mathrm{c}$ levels $>$ $9.0 \%$ (29.5\% vs. $51.4 \%$ for osteopenia, $32.8 \%$ vs. $35.1 \%$ for osteoporosis; $P=0.022$ ) (Table 2 ).

Table 2

Prevalence of sarcopenia and osteoporosis in T2DM patients stratified by gender, age, HbA1c. n (\%).

\begin{tabular}{|c|c|c|c|c|c|c|c|c|}
\hline & & Normal & Sarcopenia & $\mathbf{P}$ & Normal & Osteopenia & Osteoporosis & $\mathbf{P}$ \\
\hline \multicolumn{9}{|l|}{ Gender } \\
\hline & $\begin{array}{l}\text { Men }(n \\
=42)\end{array}$ & $19(45.2)$ & $23(54.8)$ & 0.308 & $18(42.9)$ & $19(45.2)$ & $5(11.9)$ & 0.000 \\
\hline & $\begin{array}{l}\text { Women } \\
(n=56)\end{array}$ & $32(57.1)$ & $24(42.9)$ & & $10(17.9)$ & 18(32.1) & $28(50)$ & \\
\hline & $\begin{array}{l}\text { Total } \\
(n=98)\end{array}$ & $51(52.0)$ & $47(48.0)$ & & $28(28.6)$ & $37(37.8)$ & $33(33.6)$ & \\
\hline \multicolumn{9}{|l|}{ Age } \\
\hline & $\begin{array}{l}<65 y \\
(n=49)\end{array}$ & $25(51.0)$ & $24(49.0)$ & 1.000 & 16(32.7) & $16(32.7)$ & $17(34.6)$ & 0.528 \\
\hline & $\begin{array}{l}>65 y \\
(n=49)\end{array}$ & $26(53.1)$ & $23(46.9)$ & & $12(24.5)$ & $21(42.9)$ & 16(32.6) & \\
\hline & $\begin{array}{l}\text { Total } \\
(n=98)\end{array}$ & $51(52.0)$ & $47(48.0)$ & & $28(28.6)$ & $37(37.8)$ & $33(33.6)$ & \\
\hline \multicolumn{9}{|l|}{$\mathrm{HbA1c}$} \\
\hline & $\begin{array}{l}<9.0 \% \\
(n=61)\end{array}$ & $37(60.7)$ & 24(39.3) & 0.037 & $23(37.7)$ & 18(29.5) & $20(32.8)$ & 0.022 \\
\hline & $\begin{array}{l}>9.0 \% \\
(n=37)\end{array}$ & $14(37.8)$ & $23(62.2)$ & & $5(13.5)$ & 19(51.4) & $13(35.1)$ & \\
\hline & $\begin{array}{l}\text { Total } \\
(n=98)\end{array}$ & $51(52.0)$ & $47(48.0)$ & & $28(28.6)$ & $37(37.8)$ & 33(33.6) & \\
\hline
\end{tabular}

Sarcopenia is diagnosed by low skeletal muscle index (SMI) which defined as $<7.0 \mathrm{Kg} / \mathrm{m}^{2}$ for men and $<$ $5.4 \mathrm{Kg} / \mathrm{m}^{2}$ for women. The normal bone mass is defined as T value $>-1.0 \mathrm{SD}$, osteopenia is defined as $-1.0 \mathrm{SD}>\mathrm{T}$ value $>-2.5 \mathrm{SD}$, and osteoporosis is defined as T value $<-2.5 \mathrm{SD}$.

According to the BMD T value measured via DXA, the T2DM patients were divided into the normal BMD group ( $T$ value $>-1.0)$, osteopenia group $(-1.0>T$ value $>-2.5)$, and osteoporosis group ( $T$ value $<-2.5)$. The height and weight of the osteoporosis group significantly reduced compared with those of the normal BMD group, whereas the serum BCTX, OC, and PINP levels significantly increased. SMI, trunk muscles, skeletal muscle parameters, lumbar spine BMC, lumbar spine BMD, femoral BMC, and femoral BMD in the osteoporosis group decreased significantly (Table 3). 
Table 3

Comparison of various parameters of T2DM patients with differently BMD T value.

\begin{tabular}{|c|c|c|c|c|}
\hline & normal & osteopenia & osteoporosis & $\mathbf{P}$ \\
\hline $\mathrm{n}$ & 28 & 37 & 33 & \\
\hline Age (y) & $64.54 \pm 8.03$ & $66.51 \pm 8.13$ & $66.24 \pm 8.88$ & 0.609 \\
\hline Duration of diabetes (y) & $15.04 \pm 7.90$ & $12.37 \pm 8.10$ & $14.04 \pm 7.91$ & 0.395 \\
\hline Height (cm) & $163.04 \pm 21.93$ & $162.76 \pm 9.18$ & $155.88 \pm 6.10^{\star} \#$ & 0.057 \\
\hline Weight (Kg) & $72.64 \pm 10.21$ & $65.68 \pm 10.93^{\star}$ & $58.44 \pm 11.17^{\star}$ & 0.000 \\
\hline HbA1c (\%) & $8.12 \pm 1.05$ & $8.94 \pm 2.19$ & $8.61 \pm 1.98$ & 0.219 \\
\hline BCTX (ng/ml) & $0.23 \pm 0.14$ & $0.28 \pm 0.15$ & $0.39 \pm 0.18^{\star} \#$ & 0.001 \\
\hline $\mathrm{OC}(\mathrm{ng} / \mathrm{ml})$ & $9.25 \pm 4.45$ & $10.35 \pm 3.55$ & $14.70 \pm 5.45^{\star} \#$ & 0.000 \\
\hline P1NP (ng/ml) & $29.93 \pm 13.53$ & $36.92 \pm 14.02$ & $48.76 \pm 22.56^{\star} \#$ & 0.000 \\
\hline 25-OH-D (ng/ml) & $20.61 \pm 7.86$ & $21.49 \pm 8.91$ & $19.97 \pm 9.02$ & 0.763 \\
\hline Body fat $\%$ & $30.34 \pm 6.69$ & $31.12 \pm 6.29$ & $33.25 \pm 5.89$ & 0.169 \\
\hline $\mathrm{SMI}\left(\mathrm{kg} / \mathrm{m}^{2}\right)$ & $6.87 \pm 0.98$ & $6.39 \pm 1.12$ & $5.68 \pm 0.93^{\star} \#$ & 0.000 \\
\hline Trunk MM (Kg) & $23.66 \pm 34.09$ & $21.25 \pm 37.57^{\star}$ & $18.15 \pm 30.83^{\star} \#$ & 0.000 \\
\hline Skeletal muscle parameters (\%) & $59.27 \pm 7.12$ & $58.40 \pm 6.17$ & $55.35 \pm 6.58^{*}$ & 0.049 \\
\hline Lumbar spine BMC (g) & $76.52 \pm 18.10$ & $58.92 \pm 12.99 *$ & $44.45 \pm 8.84^{\star} \#$ & 0.000 \\
\hline Femur BMC (g) & $38.89 \pm 7.70$ & $31.22 \pm 7.70 *$ & $24.03 \pm 4.70 * \#$ & 0.000 \\
\hline Lumbar spine BMD $\left(\mathrm{g} / \mathrm{cm}^{2}\right)$ & $1.10 \pm 0.13$ & $0.91 \pm 0.16^{\star}$ & $0.77 \pm 0.10^{\star} \#$ & 0.000 \\
\hline Femur BMD $\left(\mathrm{g} / \mathrm{cm}^{2}\right)$ & $0.99 \pm 0.09$ & $0.83 \pm 0.08^{*}$ & $0.73 \pm 0.10^{*} \#$ & 0.000 \\
\hline \multicolumn{5}{|c|}{$\begin{array}{l}\text { Notes: Data are expressed as the mean } \pm \text { standard deviation or } \% \text {. * refers to patients with normal, } \mathrm{P}<0.05 \\
\text { \# refers to patients with osteopenia. Abbreviations: } \mathrm{SBP}=\text { systolic blood pressure; } \mathrm{FBG}=\text { fasting plasma } \\
\text { glucose; HbA1C = glycated hemoglobin; B-CTX = B collagen specific sequences; } \mathrm{OC}=\text { osteocalcin; } \mathrm{P} 1 \mathrm{NP}= \\
\text { propeptide of type } 1 \text { procollagen, } 25-\mathrm{BH}-\mathrm{D}=25 \text {-hydroxyvitamin } \mathrm{D} ; \mathrm{SMI}=\text { skeletal muscle index; Trunk MM } \\
\text { = Trunk muscle mass; } \mathrm{BMC}=\text { bone mineral content; } \mathrm{BMD}=\text { bone mineral density. }\end{array}$} \\
\hline
\end{tabular}

Finally, a multivariate logistic regression analysis was performed on sarcopenia and osteoporosis in patients with T2DM. In the univariate analysis, height, weight, body fat content, and BCTX levels were important factors for sarcopenia, and height, FBG, ASMI, and BCTX, OC, PINP, and 25(OH)D levels were significant factors for osteoporosis. Sarcopenia was associated with a higher height $(\mathrm{OR}=1.524,95 \% \mathrm{Cl}=1.196-1.698$, $\mathrm{P}=0.000)$, lower body weight $(\mathrm{OR}=0.735,95 \% \mathrm{Cl}=0.640-0.844, \mathrm{P}=0.000)$, and higher body fat content (OR $=1.211,95 \% \mathrm{Cl}=1.046-1.402, \mathrm{P}=0.011)$. Meanwhile, osteoporosis was correlated to a lower SMI $(\mathrm{OR}=0.178$, $95 \% \mathrm{Cl}=0.044-0.817, \mathrm{P}=0.015)($ Table 4$)$. 
Table 4

Multivariable logistic regression analysis of sarcopenia and osteoporosis in T2DM patients.

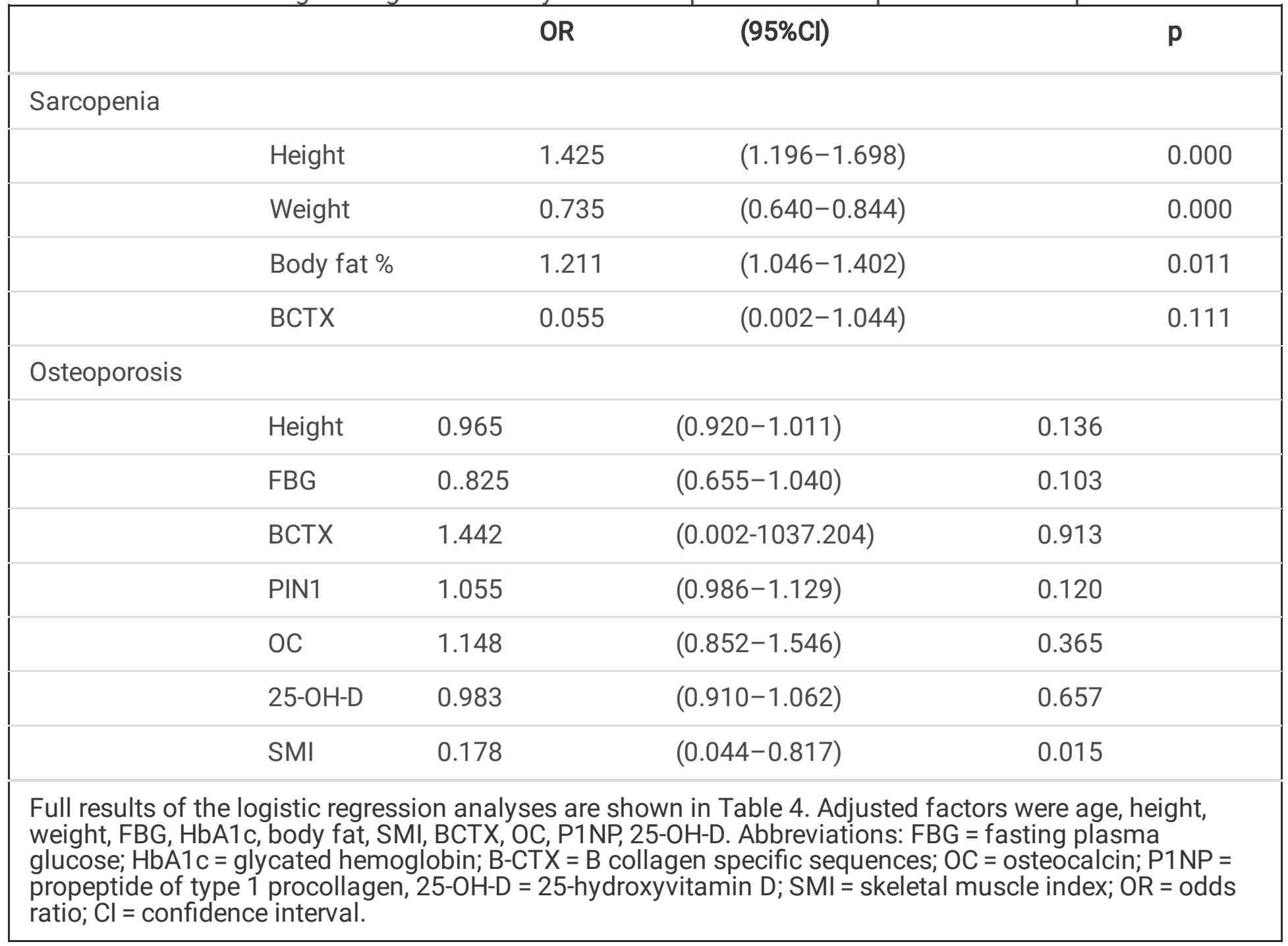

\section{Discussion}

Sarcoidosis is a common chronic complication of T2DM. According to the diagnostic criteria of the Asian Working Group for Sarcopenia, the prevalence rate of sarcopenia in the general elderly population was 4.1\%-11.5\% [11], and the probability of sarcopenia in patients with T2DM was three times higher than that of non-diabetic patients [5]. In a recent cross-sectional study in China, the incidence of sarcopenia was high at $28 \%$ in T2DM patients aged $>65$ years [12]. In this study, the prevalence rate of sarcopenia was $48.0 \%$, which was higher than that of other studies. This result may be attributed to the inclusion of hospitalized patients. The T2DM patients in this study had poor glycemic control, with an average HbA1c level of $8.59 \pm 1.87 \%$. In the Chinese cross-sectional study, the HbA1c level of the participants ranged from 7.5-8.1\% [12]. We found a trend of decreasing SMI with an increase in HbA1c levels in T2DM patients. In addition, the incidence of sarcopenia in T2DM patients with an $\mathrm{HbA} 1 \mathrm{c}$ level $>9.0 \%$ was significantly greater than that in patients with an $\mathrm{HbA} 1 \mathrm{c}$ level $<9.0 \%$. A longitudinal cohort study in Baltimore, the USA, showed that $\mathrm{HbA} 1 \mathrm{c}$ level could predict the decline in muscle mass and strength [13]. Moreover, the relationship between $\mathrm{HbA} 1 \mathrm{c}$ level and muscle mass was U-shaped, and the muscle mass in the highest HbA1c quartiles (>6.1\%) and in the lowest $\mathrm{HbA} 1 \mathrm{c}$ quartiles (< $5.5 \%$ ) significantly decreased. Patients with T2DM with an $\mathrm{HbA} 1 \mathrm{c}$ level higher than $8.0 \%$ were 
three to five times at higher risk of limited lower extremity access than those with an HbA1c level > 5.5\% [14]. A cross-sectional study showed that the average $\mathrm{HbA} 1 \mathrm{c}$ levels were $7.9 \%$ in T2DM patients without sarcopenia and $8.4 \%$ in T2DM patients with sarcopenia [15].

Higher blood glucose or HbA1c levels may lead to an increased risk of sarcopenia via a variety of mechanisms. The main factors are insulin resistance and advanced glycation end products (AGEs). Insulin resistance is a characteristic of T2DM, and various inflammatory markers, including interleukin-6 (IL-6), tumor necrosis factor alpha (TNF-a), and C-reactive protein (CRP), are correlated to insulin resistance. Muscle protein metabolism includes muscle protein synthesis and muscle protein breakdown. Muscle protein breakdown is regulated by inflammatory signaling in the four main proteolytic pathways: ATP-dependent ubiquitinproteasome pathway, calpains, macrophage autophagy, and cell apoptosis [16]. AGEs are produced via the non-enzymatic binding of glucose, proteins, and lipids, and they can induce oxidative stress and chronic inflammation, leading to tissue damage. Skin autofluorescence (AF) is a marker of AGE accumulation in the skin. A cross-sectional study in Japan found that AF in patients with T2DM is negatively correlated to muscle mass and strength, and it is a risk factor for sarcopenia [17]. In addition, diabetic microangiopathy, peripheral neuropathy, malnutrition, testosterone, and vitamin D deficiency are involved in the development of sarcopenia in T2DM [18]. An increase in HbA1c level leads to the aggravation of blood glucose disorder and the risk of complications. Thus, patients with T2DM are at increased risk of sarcopenia.

The BMD of T2DM patients may be overestimated due to overweight or obesity. However, the risk of fractures is higher in these patients than in non-diabetic patients. The RRs of hip fracture, vertebral fracture, and all fractures in patients with T2DM increased by $1.27,1.74,1.22$, respectively [19]. In a cross-sectional study, bone microstructure was measured via high-resolution peripheral quantitative computed tomography, and bone material strength index (BMSI) was calculated using a bone indentation osteoprobe. Moreover, high porosity and low BMSI of the radial cortex were observed in women with T2DM [20]. The decrease in bone strength may cause an increased risk of fracture in T2DM patients.

A study in Vietnam conducted DXA, and the iNsight Software was used to evaluate the trabecular bone score (TBS). Results showed that women with pre-diabetes $(5.7 \%<\mathrm{HbA} 1 \mathrm{c}$ level $<6.4 \%)$ and diabetes (HbA1c level > $6.4 \%$ ) had lower TBS than patients with normal blood glucose levels. Moreover, the TBS and HbA1c levels had a significant negative correlation [21]. In this study, the prevalence rate of osteopenia and osteoporosis in patients with an $\mathrm{HbA} 1 \mathrm{c}$ level $>9.0 \%$ increased significantly; compared with patients with normal BMD, those with osteopenia and osteoporosis had increased HbA1c levels. Hyperglycemia, gastrointestinal hormone response, microvascular complications, and drug therapy have effects on the bone of T2DM patients. The accumulation of AGEs in the bone caused a non-enzymatic cross-linking of type 1 collagen [22], which affected the material properties of the bone. Type 1 collagen modified by AGEs also inhibited the differentiation and activity of osteoblasts [23]. Poor glycemic control increases the risk of fracture in patients with T2DM.

The skeletal muscle and bone are interdependent anatomically, and they interact mechanically and physically. Moreover, the muscle and bone can secrete cytokines, such as interleukin, prostaglandin (PGE), OC, OPG, and RANK. These structures interact with each other via paracrine signaling, and PGE2 secreted by bone cells can promote muscle development. Moreover, $\mathrm{OC}$ can regulate muscle mass. The adult skeletal muscle expresses 
myostatin, which may regulate bone density. In myostatin-deficient mouse model, cortical bone mineral density increased in the distal femur. In addition, muscle reduction could aggravate insulin resistance and promote the development of T2DM, thereby affecting bone health [24].

Sarcopenia and osteoporosis have common causes, which include increased inflammatory factor activity and decreased secretion of sex and growth hormones [25]. Sarcopenia is a risk factor of osteoporosis, and osteoporosis also increases the incidence of sarcopenia. This study found that, the SMI trunk muscle and skeletal muscle parameter of T2DM patients with osteopenia and osteoporosis significantly decreases compared with those of T2DM patients with normal BMD. The logistic regression analysis revealed that SMI was a risk factor of osteoporosis. The risk of osteoporosis was higher by 3.89 times in men with sarcopenia and 1.87 times in women with sarcopenia [26]. In Japan, the incidence of sarcopenia in women with acute osteoporotic vertebral fractures was significantly higher than that in non-fractured women. Moreover, leg muscle reduction and sarcopenia were independent risk factors for acute osteoporotic vertebral fractures [27]. Studies in China also found that sarcopenia is an independent risk predictor for osteoporotic vertebral compression fractures [28]. In another study, osteoporosis patients were at risk of muscle strength decline [29]. The pathogenesis of sarcopenia and osteoporosis interacts with each other, and they often have a vicious cycle. This process can be aggravated by insulin resistance and chronic inflammation in T2DM patients.

This study had several limitations. First, the number of participants in this study was relatively small. Second, this study only included participants who were hospitalized, and a control group of non-diabetic patients was not included. Third, this study did not evaluate muscle strength and could not comprehensively evaluate sarcopenia. Fourth, this was a retrospective cross-sectional study, the causal relationship between sarcopenia and osteoporosis in patients with T2DM could not be assessed. Therefore, further research must be conducted to validate the relationship between sarcopenia and osteoporosis in T2DM patients, particularly those with poor blood glucose control.

\section{Conclusion}

In this study, based on the muscle mass and BMD of T2DM patients with a high $\mathrm{HbA1c}$ level, the prevalence of sarcopenia and osteoporosis was high in patients with an $\mathrm{HbA} 1 \mathrm{c}$ level $>9 \%$, and the $\mathrm{SMI}$, trunk muscle mass and skeletal muscle parameter of T2DM patients with osteoporosis decreased significantly. Moreover, SMI was considered a risk factor of T2DM in patients with osteoporosis.

\section{Declarations}

\section{Ethics approval:}

All procedures performed in studies involving human participants were in accordance with the ethical standards of the institutional and/or national research committee and with the 1964 Helsinki declaration and its later amendments or comparable ethical standards.

\section{Consent for publication:}


All authors in this study agreed to publication.

\section{Availability of data and material:}

The data in this study is transparency.

\section{Competing interests:}

all authors in this study declare that they have no conflict of interest.

\section{Funding:}

This study had no funding.

\section{Author's contributions:}

FLN conceptualization, investigation, original draft; ZS methodology, review and editing; MD investigation; LB resources; SLW resources; ZL data curation; TFY resources; SHP resources, data curation.

\section{Acknowledgements:}

none.

\section{References}

1. Limin Wang P, Gao M, Zhang, et al. Prevalence and ethnic pattern of diabetes and prediabetes in China in 2013. JAMA. 2017;317:2515-23.

2. Ali S, Garcia JM. Sarcopenia, cachexia and aging: diagnosis, mechanisms and therapeutic options. Gerontology. 2014;60:294-305.

3. Trierweiler H, Kisielewicz G, Hoffmann JT,et al. Sarcopenia: a chronic complication of type 2 diabetes mellitus. Diabetol Metab Syndr. 2018;10:25.

4. Park SW, Goodpaster BH, Strotmeyer ES, et al. Decreased muscle strength and quality in older adults with type 2 diabetes: the health, aging, and body composition study. Diabetes. 2006;55:1813-8.

5. Kim TN, Park MS, Yang SJ, et al. Prevalence and determinant factors of sarcopenia in patients with type 2 diabetes: the Korean sarcopenic obesity study (KSOS). Diabetes Care. 2010;33:1497-9.

6. Fung FY, Yi Ling Eileen Koh, et al. Prevalence of and factors associated with sarcopenia among multiethnic ambulatory older Asians with type 2 diabetes mellitus in a primary care setting. BMC Geiatr. 2019; 19:122.

7. De Liefde II, Van Der Klift M, De Laet CE, et al. Bone mineral density and fracture risk in type-2 diabetes mellitus: the Rotterdam Study. Osteoporosis Int. 2005;16:1713-20. 
8. Inbal Goldshtein AM, Nguyen AE, dePapp, et al. Epidemiology and correlates of osteoporotic fractures among type 2 diabetic patients. Arch Osteoporos. 2018;13:15.

9. Cederholm T, Cruz-Jentoft S, Maggi. Sarcopenia and fragility fractures. Eur J Phys Rehabil Med. 2013;49:111-7.

10. Chen LK, Liu LK, Woo J, et al. Sarcopenia in asia: consensus re-port of the asian working group for sarcopenia. J Am Med Dir Assoc. 2014;15:95-101.

11. Chen LK, Lee WJ, Peng LN, et al. Asian Working Group for Sarcopenia. Recent advances in sarcopenia research in Asia: 2016 update from the Asian Working Group for Sarcopenia. J Am Med Dir Assoc. 2016;17:767, e1-7.

12. Mengzhao Cui X, Gang G, Wang, et al. A cross-sectional study: Associations between sarcopenia and clinical characteristics of patients with type 2 diabetes. Med (Baltim). 2020;99:e18708.

13. Kalyani RR, Metter EJ, Egan J, et al. Hyperglycemia predicts persistently lower muscle strength with aging. Diabetes Care. 2015;38:82-90.

14. Kalyani RR, Tian J, Xue QL, et al. Hyperglycemia is associated with the incidence of frailty and lower extremity mobility limitations in older women. J Am Geriatr Soc. 2012;60:1701-7.

15. Yang Q, Zhang Y, Zeng Q, et al. Correlation between diabetic peripheral neuropathy and sarcopenia in patients with type 2 diabetes mellitus and diabetic foot disease: a cross-sectional study. Diabetes Metab Syndr Obes. 2020;13:377-86.

16. Sebastiaan Dalle L, Rossmeislova K, Koppo. The role of inflammation in age-related sarcopenia. Front Physiol. 2017;8:1045.

17. Hiroyasu Mori A, Kuroda M, Ishizu, et al. Association of accumulated advanced glycation end-products with a high prevalence of sarcopenia and dynapenia in patients with type 2 diabetes. J Diabetes Investig. 2019;10:1332-40.

18. Toshihiko yanase, Yanagita I, Muta K, et al. Frailty in elderly diabetes patients. Endocr J. 2018;65:1-11.

19. Wang H, Ba Y, Xing Q, et al. Diabetes mellitus and the risk of fractures at specific sites: a meta-analysis. BMJ Open. 2019;9:e024067.

20. Nilsson AG, Sundh D, Johansson L, et al. Type 2 diabetes mellitus is associated with better bone microarchitecture but lower bone material strength and poorer physical function in elderly women: a population-based study. J Bone Miner Res. 2017;32:1062-71.

21. Lan T, Ho-Pham B, Tran, An T, Do, et al. Association between pre-diabetes, type 2 diabetes and trabecular bone score: the Vietnam osteoporosis. Diabetes Res Clin Pract. 2019;155:107790.

22. Saito M, Fujii K, Mori Y, et al. Role of collagen enzymatic and glycation induced cross-links as a determinant of bone quality in spontaneously diabetic WBN/Kob rats. Osteoporos Int. 2016;17:1514-23.

23. Katayama Y, Akatsu T, Yamamoto M, et al. Role of nonenzymatic glycosylation of type I collagen in diabetic osteopenia. J Bone Miner Res. 1996;11:931-7.

24. Isaacson J, Brotto M. Physiology of mechanotransduction: how do muscle and bone 'talk' to one another? Clin Rev Bone Miner Metab. 2014;12:77-85.

25. Tagliaferri C, Wittrant Y, Davicco MJ, et al. Muscle and bone, two interconnected tissues. Ageing Res Rev. 2015;21:55-70. 
26. Sangmo H, Woong Hwan Choi. The effects of sarcopenia and obesity on femur neck bone mineral desity in elderly Korean men and women. Osteoporosis Sarcopenia. 2016;2:103-9.

27. Tetsuro Hida H, Shimokata Y, Sakai, et al. Sarcopenia and sarcopenic leg as potential risk factors for acute osteoporotic vertebral fracture among older women. Eur Spine J. 2016;25:3424-31.

28. Wang WF, Lin CW, Xie CN, et al. The association between sarcopenia and osteoporotic vertebral compression refractures. Osteoporosis Int. 2019;30:2459-67.

29. Tamura H, Miyamoto T, Tamaki A, et al. Osteoporosis complication is a risk factor for frailty in females with type 2 diabetes mellitus. J Phys Ther Sci. 2019;31:621-4. 